\title{
Comparative Analysis of Static and Dynamic Performance of Nonpneumatic Tire with Flexible Spoke Structure
}

\author{
Zifeng Zhang - Hongxun Fu* - Xuemeng Liang - Xiaoxia Chen - Di Tan \\ Shandong University of Technology, School of Transportation and Vehicle Engineering, China
}

Based on ABAQUS software, the three-dimensional finite element models of 195/50R16 radial tire and three kinds of nonpneumatic tire, i.e., spoke plate, honeycomb and grid type, are established, and the static and dynamic performance of the four finite element models of tire are analysed. The results show that in the static condition analysis, the ground pressure of the nonpneumatic tire is distributed on both sides of the tread; the stress concentration of the nonpneumatic tire mainly occurs in the grounding area near the support spoke; the deformation area of nonpneumatic tire mainly appears in the area of grounding and adjacent to the grounding spoke; In the analysis of the tire's steady rolling condition, the ground imprint of a nonpneumatic tire is similar to that of a bar rectangle, and the ground pressure distribution is relatively uniform. The static and dynamic characteristics of honeycomb nonpneumatic tire are close to that of a radial tire. The research work of this paper will provide some reference for the structural design and parameter optimization of nonpneumatic tires.

Keywords: nonpneumatic tire, ground pressure distribution, load-carrying characteristics, dynamic characteristics

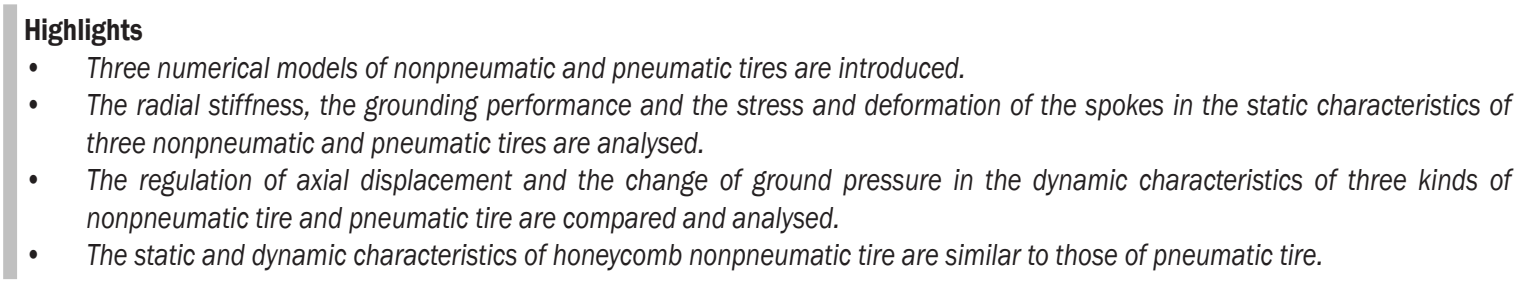

\section{INTRODUCTION}

The nonpneumatic tire does not use compressed air, which is an essential part of the pneumatic tire; instead it relies on the wheel's integrated structure. Compared with the pneumatic tire, the nonpneumatic tire has the advantages of being maintenance-free, explosion-proof, puncture-proof and has a strong bearing capacity. According to China's transportation department, the proportion of traffic accidents caused by pneumatic tires is about $50 \%$ [1]. Many scholars in the tire industry analyse and study the structure and bearing capacity of flexible structure nonpneumatic tire [2] to [4]. Such tires are safer than pneumatic tires. The most representative is the design of honeycomb structure; the structure of which has been studied for more than 30 years, Honeycomb materials are mainly used in military equipment to absorb high energy impact [5] to [7]; they are also used in for structural designs of high strength and low density [8].

In 2008, a honeycomb tire without internal pressure was developed by the Madison Polymer Research Center, Wisconsin, USA [9]. In order to improve the strength and vibration performance of the wheel, the honeycomb hexagon structure is mutually supported based on the bionics principle; the optimal design of the structure can improve the strength of the wheel, avoid the problem of tire burst and damage, and the wheel structure also has the advantages of low noise and low friction heat generation. A design schematic of a mechanical elastic safety wheel with a non-inflatable structure was put forward in [10] and [11].

Gawwad et al. [12] studied the interaction between tire and ground, and analysed the influence of tire camber on tire performance. Tonuk and Unlusoy [13], Goldstein [14], and Oishi et al. [15] explored the magnitude of the force and the moment in the tire imprint under rolling, steering and braking conditions, as well as the steering stiffness, braking stiffness and return stiffness of the whole tire. Baranowski et al. [16] set up a multistage testing procedure of the tire and proved the accuracy of the test results and the finite element results. Kucewicz et al. [17] evaluated the effect of mesh on finite element results by studying the mesh sensitivity. Baranowski et al. [18] studied the mechanical properties of rubber at different speeds under quasi-static and strong dynamic conditions. Padovan et al. [19], Pldaparti [20] and Ebbott [21] established a three-dimensional model of a pneumatic tire, and explored the mechanical properties of cordrubber composite and its influence on tire properties through the finite element software. Kim et al. [22] and [23] explored the grounding characteristics of 
a honeycomb nonpneumatic tire under different vertical loads and different honeycomb structures, and compared them with the traditional pneumatic tire under the same working conditions based on ABAQUS software. Kim et al. [24] applied ABAQUS software to study the static grounding characteristics and steady rolling of a honeycomb nonpneumatic tire, and discussed the factors affecting its vibration characteristics. Kim et al. [25] and $\mathrm{Ju}$ et al. [26] conducted a parametric study and experimental design of the honeycomb nonpneumatic tire through the finite element analysis, explored the influence of three variables, namely, spoke thickness, spoke angle and shear band thickness, on the rolling resistance of the nonpneumatic tire, and optimized its geometric structure. Song et al. [27] used the finite element method to study the temperature field distribution of tire in a rolling state. Nishiyama et al. [28] developed an algorithm for transforming finite element and discrete element to improve the calculation efficiency.

Based on ABAQUS software, this paper makes static and dynamic analysis of radial tire and three kinds of nonpneumatic tires with different structures, the main research contents are as follows: (1) The tire's finite element model is established, including radial pneumatic tire, spoke plate nonpneumatic tire, honeycomb nonpneumatic tire and grid type nonpneumatic tire; (2) Based on ABAQUS/Standard module, the static analysis and comparison of the tire finite element model are carried out, including load-bearing characteristics, grounding imprint, stress and deformation of spoke plate, etc.; (3) Based on the ABAQUS/Standard module, the dynamic performance of the tire finite element model is compared and analysed, including the displacement regulation of the tire centre point and the distribution of the ground pressure during the rolling process.

\section{THE ESTABLISHMENT OF TIRE FINITE ELEMENT MODEL}

\subsection{Pneumatic Tire Reference Model}

Numerical analysis is an important part of tire research. By setting different material properties, different model structural parameters and different boundary constraints, various characteristics of tire can be effectively studied [29] and [30]. Based on ABAQUS software, a three-dimensional finite element model of 195/50R16 radial tire is established, as shown in the left part of Fig. 1. The material properties of different components of radial pneumatic tire are different, so the pneumatic tire should be divided into different zones to give different material properties to the tread, crown belt layer, belt layer\#1, belt layer\#2, inside liner, sidewall, bead wire and other parts. In this paper, the method of defining the rebar element in the rubber matrix element is used to establish the model.
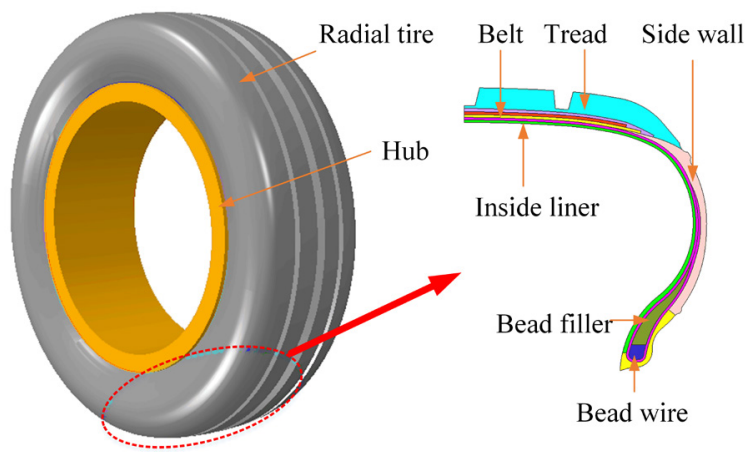

Fig. 1. 3D finite element model of pneumatic tire

\subsubsection{Material Characteristics of Pneumatic Tire}

Rubber material is a kind of hyperelastic material, which has approximate volume incompressibility and nonlinearity. In order to better describe the mechanical properties of rubber materials in tire, the Neo-Hookean model, the most common molecular statistical constitutive model of rubber materials, is selected in this paper. Table 1 shows the parameters used in the model; the table is provided by China Triangle Tire co., Ltd. The strain energy function of Neo-Hookean model describes the compressible rubber material as follows:

$$
W=\frac{1}{2} \lambda(\ln J)^{2}+\frac{1}{2} \mu\left(I_{1}-3\right)-\mu \ln J .
$$

The strain energy function of Neo- Hookean model describes the incompressible rubber material as follows:

$$
W=C_{10}\left(I_{1}-3\right),
$$

where $W$ is strain energy density, $\lambda$ elongation, $J$ volume ratio before and after deformation, $\mu$ material stress class constant, $\bar{I}_{1}$ the first invariant of principal elongation ratio, and $C_{10}$ material constants.

Table 1. Rubber material parameters

\begin{tabular}{lccc}
\hline Rubber material & $C_{10}$ & $D_{1}$ & Density $\left[1 \mathrm{e}-9 \mathrm{~T} / \mathrm{mm}^{3}\right]$ \\
\hline Tread & 0.5 & 0.04 & 1.11 \\
\hline Sidewall & 0.6 & 0.03 & 1.12 \\
\hline Inside liner & 1.5 & 0.01 & 1.10 \\
\hline Apex & 6.0 & 0.003 & 1.10 \\
\hline
\end{tabular}

The two layers of reinforcement embedded in the tread are made of high-strength steel; the elastic 
modulus $E=2.1 \times 10^{5} \mathrm{MPa}$ and Poisson's ratio $\mu=0.29$. The thickness of the reinforcement layer is $0.5 \mathrm{~mm}$. This steel wire material property is also applicable to the nonpneumatic tire; this material property is no longer described for the nonpneumatic tyre part.

\subsection{Structural Parameters and Modeling of the Nonpneumatic Tire}

The static analysis and dynamic comparative analysis are carried out for the tire. Therefore, in the modelling stage, the control variables are the same for the general structural parameters of the spoke, honeycomb and grid type nonpneumatic tire. Only the number and structure of spokes as supporting parts is different. The

a)
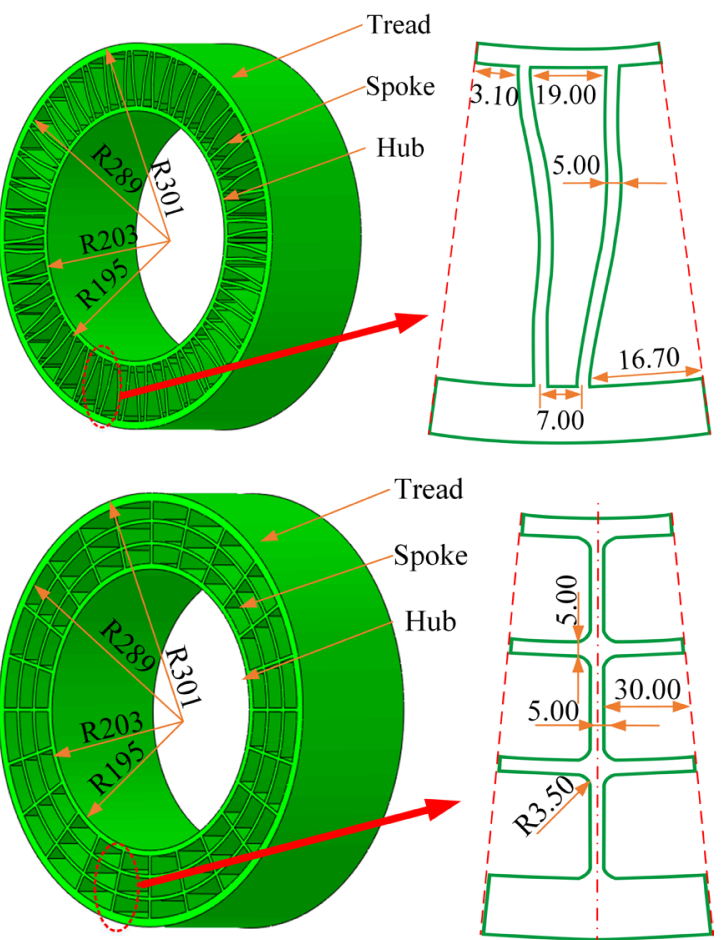

b)

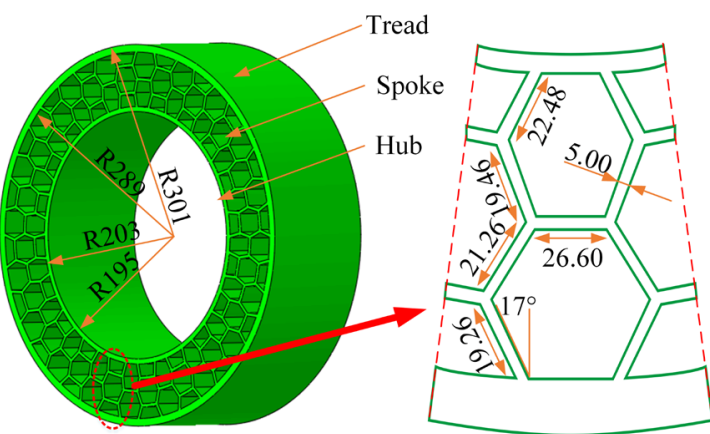

Fig. 2. 3D finite element models; a) spoke, b) grid, and c) honeycomb type of nonpneumatic tires unified structural parameters are as follows: The outer diameter is $602 \mathrm{~mm}$, the inner diameter is $390 \mathrm{~mm}$, the tread thickness is $12 \mathrm{~mm}$, and the spoke thickness is $5 \mathrm{~mm}$. The three-dimensional finite element models of spoke, honeycomb and grid type nonpneumatic tires are shown in Fig. 2.

\subsubsection{Material Characteristics of the Nonpneumatic Tire}

The nonpneumatic tire mainly consists of the following parts: (1) tread; (2) flexible spokes; (3) two reinforcing layers embedded in the tread. The tread is made of rubber with a thickness of $12 \mathrm{~mm}$ and is located at the outermost layer of the tire. The relationship between the two reinforcing layers and tread position is shown in Fig. 3.

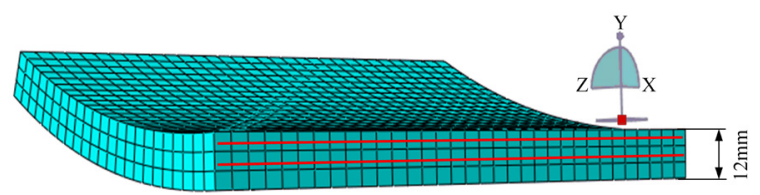

Fig. 3. Two reinforcing layers and tread position relationship

The tread rubber is dumbbell-shaped, and the upper and lower ends are fixed on the tensile tester, the stress-strain relationship is obtained by the tensile stress-strain tester (Instrument model: WDW-100), as shown in Fig. 4.

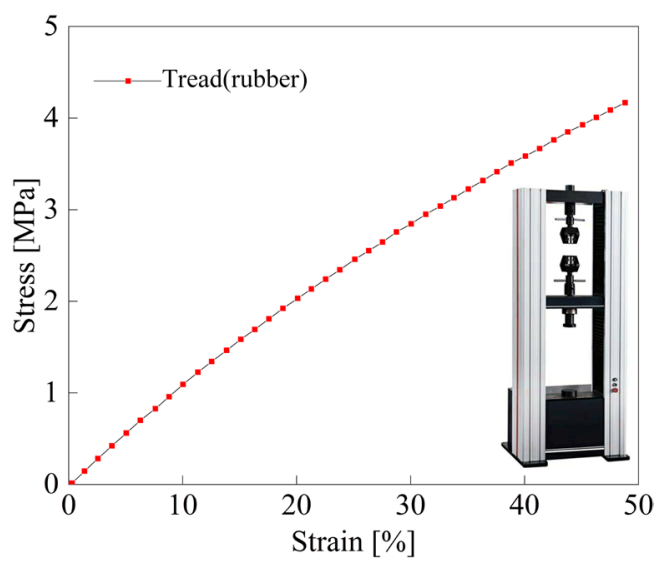

Fig. 4. Material parameters of tread rubber

Polyurethane not has only the high elasticity of rubber, but also high strength of plastic, excellent comprehensive performance, wear-resistant, flameretardant characteristics, long service life, simple production process, green environmental protection and many other characteristics. It is an ideal material for manufacturing tires. The carcass of the tire is made of polyurethane elastic material. According to the 
literature, the relationship between stress and strain is shown in Fig. 5 [31].

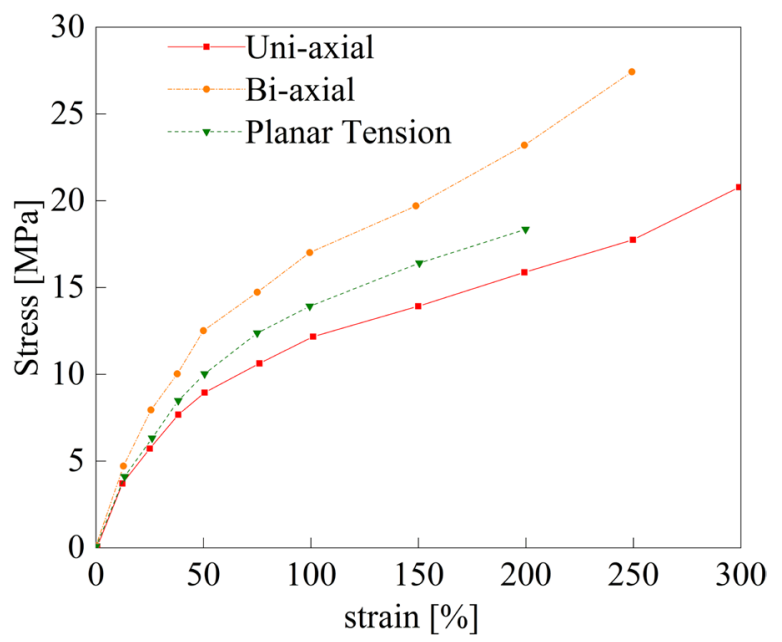

Fig. 5. Stress and strain relationships of uniaxial, biaxial and planar tension in nonpneumatic tire

\subsection{Finite Element Simulation Settings}

Hexahedral elements have high accuracy and good convergence, and are thus better for use as solid elements. Therefore, a C3D8R [32] unit is used for ground structures and nonpneumatic tire structures. Among other uses, SFM3D4 units are used for the belt and cord layers in the pneumatic tire, and an M3D4R unit is used for the reinforcement layer in the nonpneumatic tire. The same part structure of the four tires is divided by the same mesh type and mesh size. The number of elements for nonpneumatic and pneumatic tires is controlled between 100,000 and 120,000 , depending on the specific tire structure; the number of elements for the road surface is unified at 8,000 . The number of elements and nodes is no longer stated separately. Both static and dynamic analyses were performed using implicit algorithms. The contact properties were set as tangential behaviour and normal behaviour, and the friction coefficient was set as 0.7 using the friction formula of the penalty function.

In order to improve the calculation efficiency, the road surface is uniformly set as a rigid body, the ground to be completely fixed, the road surface as the first contact surface, and the tread as the second contact surface. The axial positions of pneumatic and nonpneumatic tires are the loading points. In order to avoid the repetition and jumble of the picture, the finite element model of inflatable tire is only used to replace the finite element model of other three types of nonpneumatic tires in Fig. 6 to show the simulation scheme of four types of tires. Both tires and rims are tied using the TIE command.

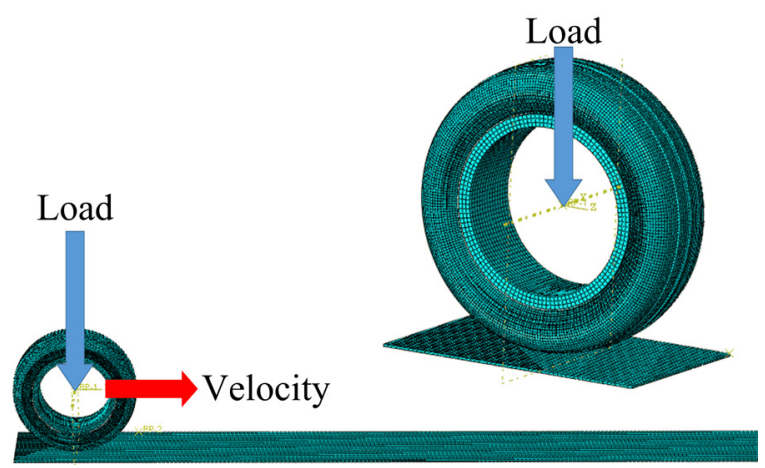

Fig. 6. Static and dynamic tire finite element simulation scheme

\section{NUMERICAL ANALYSIS OF STATIC PERFORMANCE}

In the static analysis, the main research is the deformation of the tire, so the ground and the hub are set as rigid bodies, and the ground is completely fixed, in order to reduce the calculation amount and shorten the calculation time. The static analysis of pneumatic tire includes three analysis steps: inflation, contact, and loading, while the analysis of nonpneumatic tire only includes two analysis steps: contact and loading. The vertical load of the pneumatic tire and the nonpneumatic tire is $3000 \mathrm{~N}$ in the loading analysis step, analysis and research on grounding performance of pneumatic and nonpneumatic tyres. The vertical load $(500 \mathrm{~N}$ to $6000 \mathrm{~N})$ was applied to compare the stiffness change trend of nonpneumatic tire and pneumatic tire. The large deformation switch is turned on in all analysis steps.

\subsection{Comparison of Static Load-carrying Characteristics of Tire}

\subsubsection{Radial Stiffness Analysis}

When the internal pressure of the pneumatic tire is $240 \mathrm{kPa}$, the comparison diagram of the load-carrying characteristic curve of the pneumatic tire and the nonpneumatic tire with the spoke, honeycomb and grid type formats is shown in Fig. 7, and the reference point is the centre point of the tire. In order to fully reflect the authenticity of the numerical analysis, Fig. 8 shows the static load test of the pneumatic tire.

The tire is placed on the loading mechanism to apply different radial loads (Instrument model: CSS88100), laser level instruments are used to ensure excellent level of tires, applied load, get accurate test 


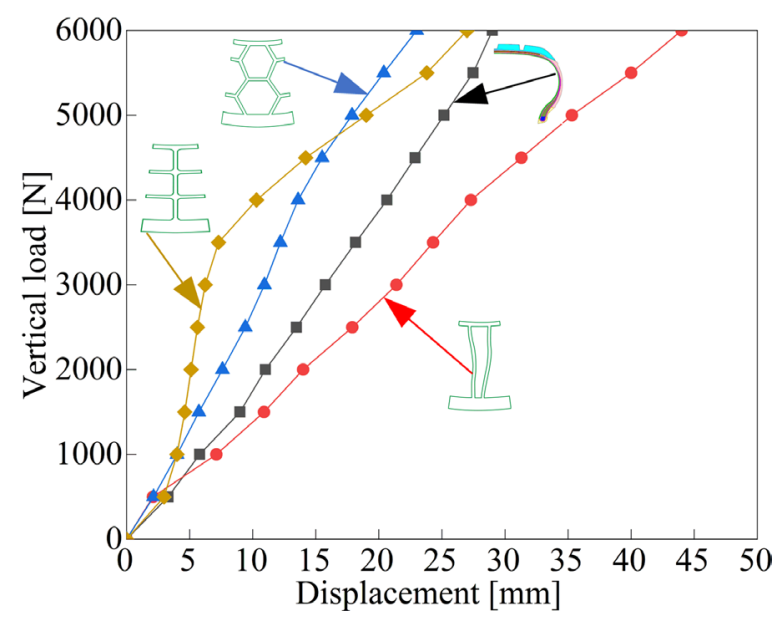

Fig. 7. Comparison of tire bearing characteristics

data. The material properties used for finite element simulation are entirely consistent with the material properties obtained from the actual tire. The error between the experimental data and the numerical analysis is within $5 \%$, which is enough to reflect the real situation.

It can be seen from the comparison diagram of tire load-bearing characteristic curve: (1) the loadcarrying characteristic curve of pneumatic tire, spoke plate and honeycomb nonpneumatic tire is approximate to the first-order function, among them, the radial stiffness of honeycomb nonpneumatic tire is the most similar to that of pneumatic tire, while the radial stiffness of spoke nonpneumatic tire is weaker; therefore, the load-carrying characteristics and vehicle driving comfort of honeycomb nonpneumatic tire are similar to those of pneumatic tire; (2) among the four types of tires, when the radial load is less than 3500 $\mathrm{N}$, the radial stiffness of the grid type nonpneumatic tire is the largest, so the bearing capacity is the best, and its radial stiffness is about 4 times of the radial stiffness of the pneumatic tire, when the vertical load is more than $3500 \mathrm{~N}$, the radial stiffness of the grid type nonpneumatic tire is similar to that of the spoke nonpneumatic tire, but the load-carrying capacity of the grid type nonpneumatic tire is much higher than that of the spoke plate nonpneumatic tire.

\subsubsection{Analysis of Grounding Performance}

Under the action of the rated load of $3000 \mathrm{~N}$, the static deformation of the pneumatic tire, spoke plate, honeycomb and grid type nonpneumatic tire is shown in Fig. 9. It can be seen that the ground pressure distribution of pneumatic tire is similar to the ellipse,

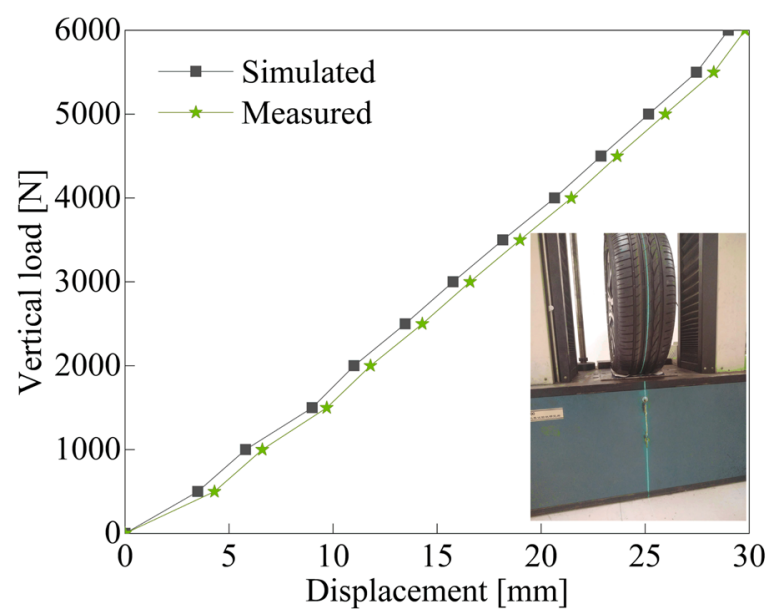

Fig. 8. Static load test of pneumatic tire

and the ground pressure concentration phenomenon appears at the groove position of the ellipse central pattern, and the ground pressure distribution presents a large to small distribution from the ellipse centre to the surrounding; The distribution of the ground pressure of the nonpneumatic tire in the form of spoke, honeycomb and grid type is similar to the bar rectangle. From the $3 \mathrm{D}$ mapping surface, it can be seen that the two sides are not closed, and the ground pressure of the nonpneumatic tire is concentrated at both sides of the connection between the flexible spoke and the tread. The transverse length of the ground pressure distribution of the spoke, honeycomb and grid type nonpneumatic tire is larger than that of the pneumatic tire, while the longitudinal width of the ground pressure distribution is smaller than that of the pneumatic tire, which improves the axial stability of the vehicle.

\subsubsection{Stress and Deformation of Spoke}

The stress and deformation nephogram of the pneumatic tire, spoke plate, honeycomb and grid type nonpneumatic tire under the rated load of $3000 \mathrm{~N}$ are shown in Fig. 10; the high stress of pneumatic tire is mainly concentrated in the ground tread and sidewall area, while the high stress of nonpneumatic tire is mainly concentrated in the spoke plate and tread belt layer. The stress peak value of the spoke nonpneumatic tire are 0.41 and 0.54 times of that of the honeycomb and grid type nonpneumatic tire, respectively, and the stress distribution of the spoke nonpneumatic tire is more uniform than that of the honeycomb and grid type nonpneumatic tire. Where the stress 
a)

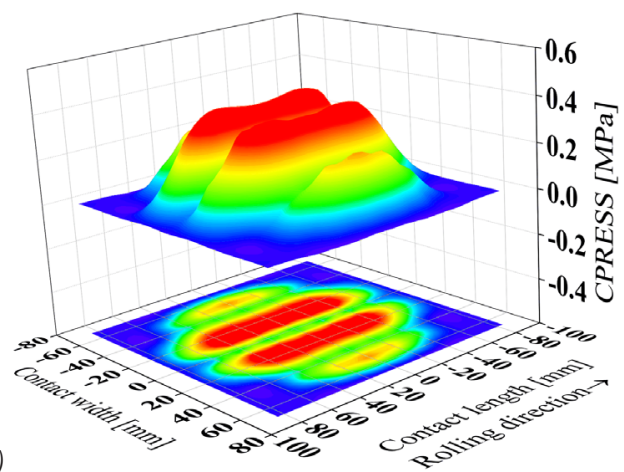

c)

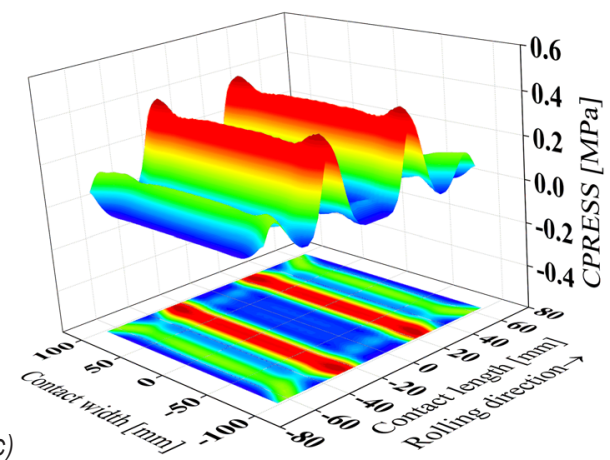

b)

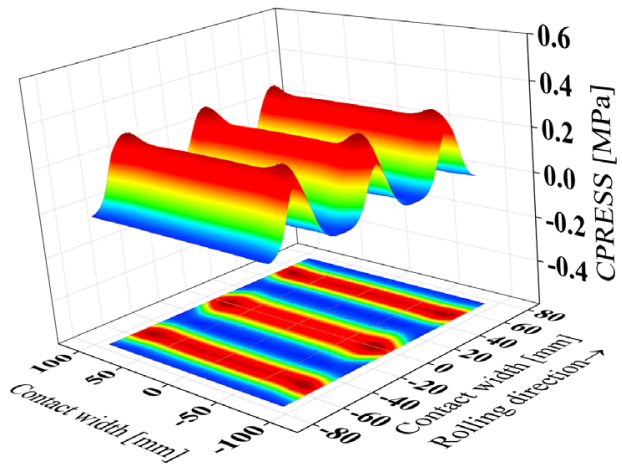

d)

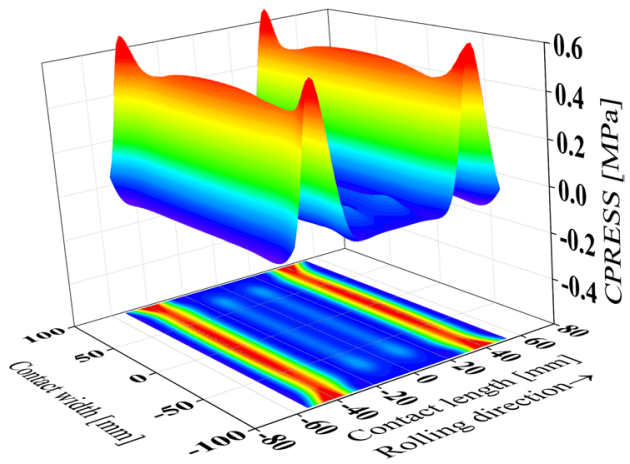

Fig. 9. Static deformation and grounding mark of a) (inflatable) pneumatic tire, b) spoke plate type nonpneumatic tire, c) honeycomb nonpneumatic tire, and d) grid type nonpneumatic tire under rated load of $3000 \mathrm{~N}$

a)

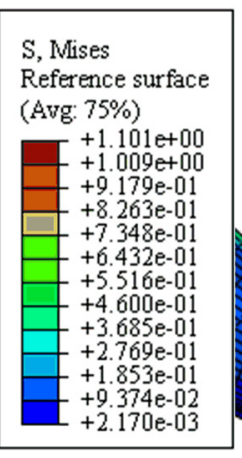

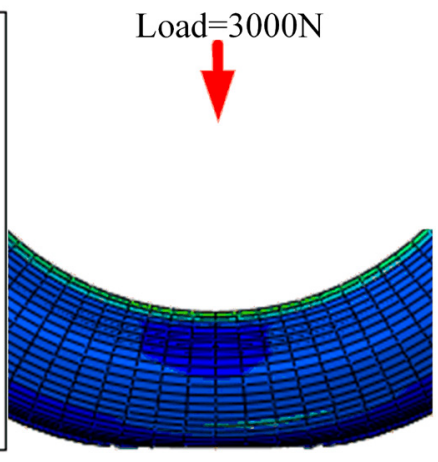

S, Mises
(Avg: $75 \%$ )
\begin{tabular}{r|r|}
\hline & $+2.804 \mathrm{e}+00$ \\
& $+2.571 \mathrm{e}+00$ \\
& $+2.337 \mathrm{e}+00$ \\
& $+2.103 \mathrm{e}+00$ \\
& $+1.870 \mathrm{e}+00$ \\
& $+1.636 \mathrm{e}+00$ \\
& $+1.402 \mathrm{e}+00$ \\
& $+1.169 \mathrm{e}+00$ \\
& $+9.350 \mathrm{e}-01$ \\
& $+7.014 \mathrm{e}-01$ \\
& $+4.677 \mathrm{e}-01$ \\
& $+2.340 \mathrm{e}-01$ \\
& $+3.390 \mathrm{e}-04$
\end{tabular}

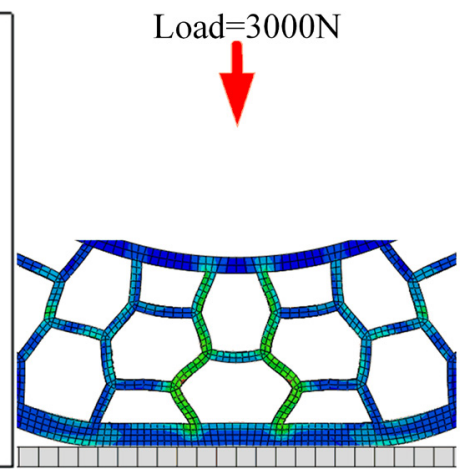

b)
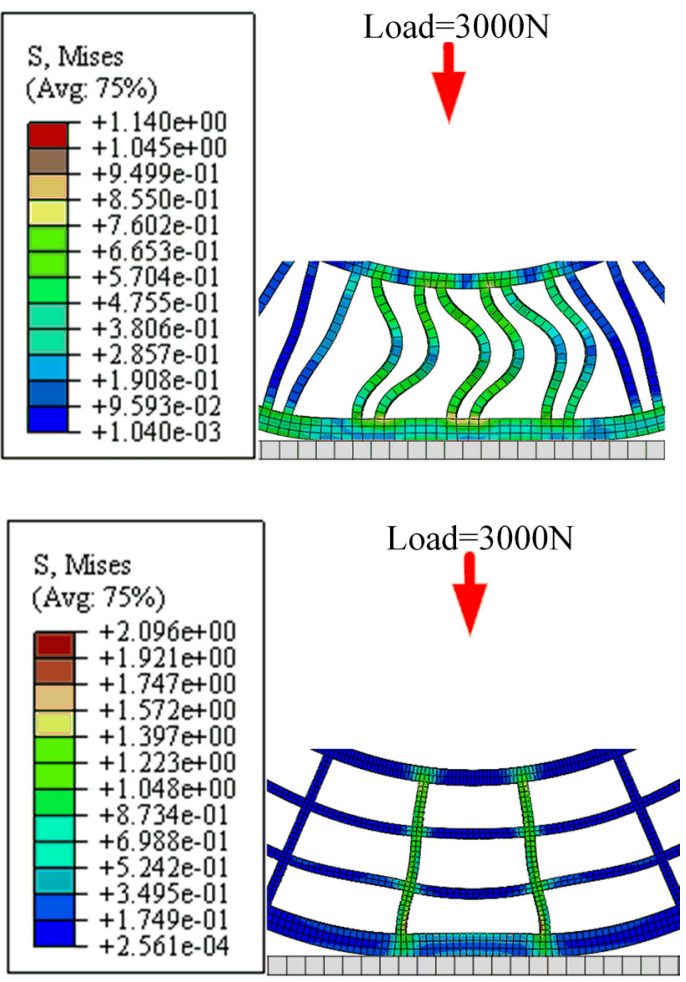

Fig. 10. Stress and deformation nephogram of a) inflatable pneumatic tire, b) spoke plate type nonpneumatic tire, c) honeycomb nonpneumatic tire and d) grid type nonpneumatic tire under rated load of $3000 \mathrm{~N}$ 
concentration is high, the strain energy density is high, which leads to a decrease of tire fatigue life.

\section{DYNAMIC FINITE ELEMENT ANALYSIS OF TIRE}

Using ABAQUS software to establish the tire steadystate rolling finite element model, this paper mainly explores the pressure change and pressure distribution of the tire ground part and the displacement regulation of the tire centre point when the tire rolls freely under the condition of the rated load of $3000 \mathrm{~N}$ and the angular speed of $31.4 \mathrm{rad} / \mathrm{s}$. The finite element model is modelled in a unified coordinate system. In the inflation analysis step, fix the central point of the pneumatic tire and apply $0.24 \mathrm{MPa}$ pressure on the inner surface of the tire to simulate the inflation condition. Grid division is the same as the type of grid division in static analysis, and it will not be described in detail.

\subsection{Displacement Regulation of Tire Center Point}

The displacement regulation of tire centre point is of great significance to vehicle driving comfort and vehicle structural stability. Fig. 11 shows the change rule of the displacement of the central point of the pneumatic tire and the nonpneumatic tire with time.

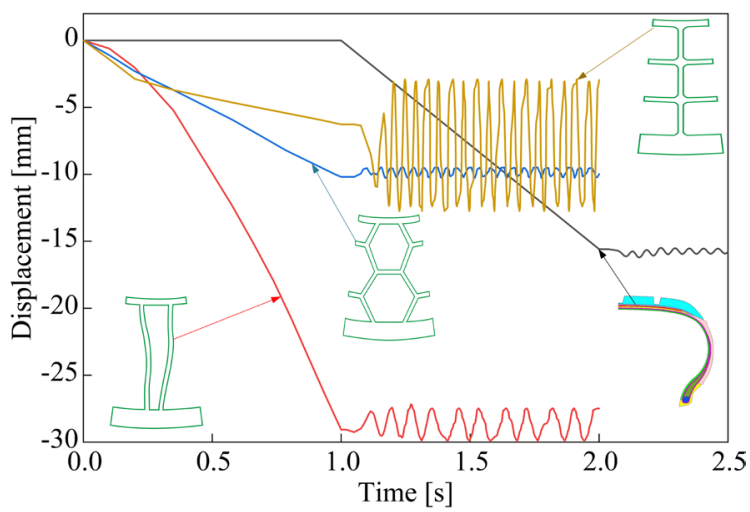

Fig. 11. Center point displacement curve of tire

1. The displacement curve of the central point of the pneumatic tire is under the inflation condition in the period of $0 \mathrm{~s}$ to $1 \mathrm{~s}$, the tire centre point is fixed; $1 \mathrm{~s}$ to $2 \mathrm{~s}$ is the loading step, and the tire centre point moves down; $2 \mathrm{~s}$ to $2.25 \mathrm{~s}$ is the acceleration step, and the angular velocity at the tire centre point increases from $0 \mathrm{rad} / \mathrm{s}$ to 31.4 $\mathrm{rad} / \mathrm{s}$; the period of $2.25 \mathrm{~s}$ to $2.5 \mathrm{~s}$ is steady rolling condition.

2. The displacement curve of the centre point of the nonpneumatic tire in the period of $0 \mathrm{~s}$ to $1 \mathrm{~s}$ is the loading step, and the centre point of the tire moves down; The period of $1 \mathrm{~s}$ to $1.2 \mathrm{~s}$ is the acceleration step, the tire angular velocity increases from 0 $\mathrm{rad} / \mathrm{s}$ to $31.4 \mathrm{rad} / \mathrm{s}$, and the displacement curve fluctuates; The period of $1.2 \mathrm{~s}$ to $2 \mathrm{~s}$ is steady rolling stage, and the vertical displacement of tire centre point changes periodically.

Under the condition of pure rolling, the angular acceleration, $\omega$ of the tire is 0 , and the tangent speed, $v$ of the centre of the tread is the forward driving speed, $v_{0}$ of the vehicle, the equation is as follows:

$$
v=r_{e} \omega_{0}=v_{0} .
$$

Fig. 12 shows the three radii of the tire. The vertical load has a direct influence on effective rolling radius and load radius. Pacejka [33] proposed a more comprehensive interpretation of the effective rolling radius of the tire.

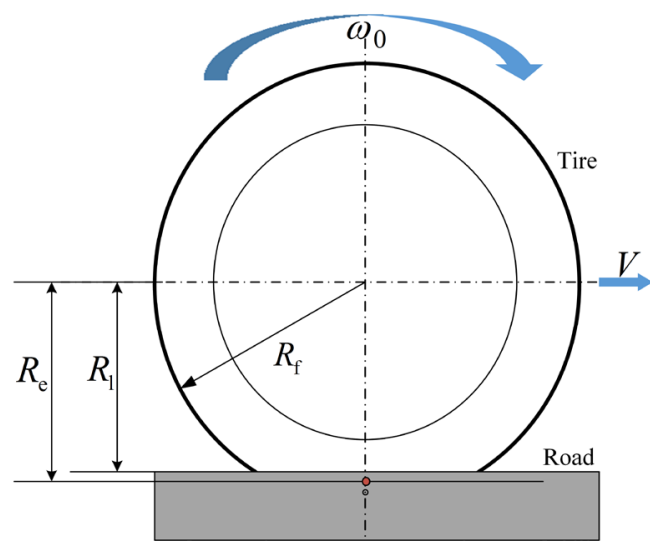

Fig. 12. The rolling radius of the tire; $R_{\mathrm{e}}$ effective rolling radius, $R_{1}$ radius of tire under load, $R_{\mathrm{f}}$ radius of tire under no load; $\omega_{0}$ pure rolling angular velocity

Both the pneumatic tire and nonpneumatic tire are deformable bodies with hysteresis, under the influence of inertia force and centrifugal force in the rolling process, the radius of each particle relative to the tire axis is different, so the tire presents the curve characteristics of wave shape in the rolling process

It can be seen from the comparison of the displacement regulation of the centre point of the nonpneumatic tire and the pneumatic tire in Fig. 9 that the fluctuation amplitude of honeycomb nonpneumatic tire is the closest to that of pneumatic tire. Among them, the honeycomb nonpneumatic tire is most similar to the pneumatic tire in driving comfort and structural stability during steady rolling. Under the action of a $3000 \mathrm{~N}$ radial load, the radial sinkage of the spoke type nonpneumatic tire is too large, and 
its driving comfort and vehicle structure stability in the steady rolling process are worse than those of the pneumatic tire, so it is not suitable for the vehicle with larger curb weight. In the steady-state driving process under the action of $3000 \mathrm{~N}$ radial load, the amplitude of the grid type nonpneumatic tire changes too much, but the sinking of the grid type nonpneumatic tire is the smallest compared with the pneumatic tire, the spoke nonpneumatic tire and the honeycomb nonpneumatic tire; therefore, it can be concluded that the structure of the grid type nonpneumatic tire needs to be optimized, the number of nonpneumatic tire units needs to be increased, and the amplitude of the nonpneumatic tire can be reduced. To increase the vehicle's driving comfort and tire grip by increasing the sinking of grid type nonpneumatic tire, the material stiffness must be improved.

\section{CONCLUSIONS}

Based on ABAQUS software, 3D finite element models of 195/50R16 radial pneumatic tire, spoke plate type nonpneumatic tire, honeycomb nonpneumatic tire and grid type nonpneumatic tire are established, and their static and dynamic analysis are carried out respectively.

1. Under the action of the rated load of $3000 \mathrm{~N}$, the grounding area of the pneumatic tire has axisymmetric deformation, and the deformation area is mainly distributed in the grounding part and sidewall; Because the rubber material of the sidewall of the radial pneumatic tire is thin, it is consistent with the actual situation.

2. The deformation area of the nonpneumatic tire is mainly distributed in the grounding part and the spokes near the grounding part. The grounding imprint of the pneumatic tire is similar to the bar shape rectangle, and the grounding part near the spoke plate has the phenomenon of ground pressure concentration; when the radial load is less than $3500 \mathrm{~N}$, the load-carrying capacity of the grid type nonpneumatic tire is the best; when the radial load is more than $3500 \mathrm{~N}$, the load capacity of honeycomb nonpneumatic tire is the best. When the polyurethane support structure of the nonpneumatic tire uses the same material model, the radial stiffness of the spoke plate nonpneumatic tire is too small, which is not suitable for vehicles with too large curb weight; however, the radial stiffness of the grid type nonpneumatic tire is too large, which is suitable for vehicles with too large curb weight; The load-carrying characteristics of the honeycomb nonpneumatic tire and radial pneumatic tire are similar.

3. When the tire is rolling, the displacement curve of the tire centre point fluctuates during acceleration, and the vertical displacement of the tire centre point changes periodically during steady rolling; the overall performance of grid type nonpneumatic tire is not ideal, so its structure needs to be further optimized.

4. In the analysis of tires' dynamic characteristics, the amplitude of their axis position not only has an inevitable relationship with the structure of tires but also has a direct correlation with the vertical load; therefore, it is necessary to reasonably choose the style and type of inflatable tire and nonpneumatic tires according to the requirements of ride comfort and vertical load conditions.

\section{ACKNOWLEDGEMENTS}

This work was supported by the National Natural Science Foundation of China under Grant 51775320 and project ZR2018PEE008 supported by Shandong Provincial Natural Science Foundation.

\section{REFERENCES}

[1] Zhao, Y.Q., Zang, L.G., Chen, Y.Q., Li, B., Wang, J. (2015). Nonpneumatic mechanical elastic wheel natural dynamic characteristics and influencing factors. Journal of Central South University, vol. 22, no. 5, p. 1707-1715, D0l:10.1007/ s11771-015-2689-1.

[2] Kim, K., Kim, S., Ju, J., Kim, D.M. (2011). Contact pressure of a nonpneumatic tire with 3D cellular spokes. Proceedings of the ASME International Mechanical Engineering Congress and Exposition, Denver, D0I:10.1115/IMECE2011-64233.

[3] Veeramurthy, M., Ju, J., Thompson, L., Summers, J.D. (2011). Optimization of nonpneumatic tire (NPT) for reducing rolling resistance. Proceedings of the ASME International Conference on Advanced Vehicle and Tire Technologies, Washington, DOl:10.1115/DETC2011-48730.

[4] Ju, J., Veeramurthy, M., Summers, J.D., Thompson, L. (2013). Rolling resistance of a nopneumatic tire having a porous elastomer composite shear band. Tire Science and Technology, vol. 41, no. 3, p. 154-173, Dol:10.2346/tire13.410303.

[5] Abd El-Sayed, F.K., Jones, R., Burgess, I.W. (1979). A theoretical approach to the deformation of honeycomb based composite materials. Composites, vol. 10, no. 4, p. 2090-214, DOI:10.1016/00104361(79)90021-1.

[6] Zhu, H.X., Mills, N.J. (2000). The in-plane non-linear compression of regular honeycombs. International Journal of Solids and Structures, vol. 37, no. 13, p. 1931-1949, DOI:10.1016/s0020-7683(98)00324-2.

[7] Bezazi, A., Scarpa, F., Remillat, C. (2005). A novel centresymmetric honeycomb composite structure. Composite 
Structures, vol. 71, no. 3-4, p. 536-364, D0l:10.1016/j. compstruct.2005.09.035.

[8] Wang, J., Hu, X., Yuan, K., Meng, W., Li, P. (2019). Impact resistance prediction of superalloy honeycomb using modified Johnson-Cook constitutive model and fracture criterion. International Journal of Impact Engineering, vol. 131, p. 6677, D0l:10.1016/j. ijimpeng. 2019. 05.001.

[9] Ju, J., Ananthasayanam, B., Summers, J.D., Joseph, P. (2010). Design of cellular shear bands of a nonpneumatic tireinvestigation of contact pressure. SAE International Journal of Passenger Cars - Mechanical Systems, vol. 3, no. 1, p. 598606, D0I:10.4271/2010-01-0768.

[10] Xiao, Z., Zhao, Y.Q., Lin, F., Zhu, M.M., Deng, Y.J. (2018). Studying the fatigue life of a nonpneumatic wheel by using finite life design for life prediction. Strojniški vestnik - Journal of Mechanical Engineering, vol. 64, no. 1, p. 56-67, Dol:10.554 5/sv-jme.2017.4695.

[11] Du, X.B., Zhao, Y.Q., Wang, Q., Fu, H.X., Lin, F. (2019). Grounding characteristics of a nonpneumatic mechanical elastic tire in a rolling state with a camber angle. Strojniški vestnik - Journal of Mechanical Engineering, vol. 65, no. 5 p. 287-296, D0l:10.5545/sv-jme.2018.5845.

[12] El-Gawwad, K.A.A., Crolla, D.A., Soliman, A.M.A., El-Sayed, F.M. (1999). Off-road tyre modelling II: effect of camber ontyre performance. Journal of Terramechanics, vol. 36, no. 1, p. 2538, D0l:10.1016/s0022-4898(98)00032-9.

[13] Tönük, E., Ünlüsoy, Y.S. (2001). Prediction of automobile tire cornering force characteristics by finite element modeling and analysis. Computers \& Structures, vol. 79, no. 13, p. 12191232, D0I:10.1016/s0045-7949(01) 00022-0.

[14] Goldstein, A.A. (1996). Finite element analysis of a quasistatic rolling tire model for determination of truck tire force and moments. Tire Science and Technology, vol. 24, no. 4, p. 278-293, D0I:10.2346/1.2137523.

[15] Ohishi, K., Suita, H., Ishihara, K. (2002). The finite element approach to predict the plysteer residual cornering force of tires. Tire Science and Technology, vol. 30, no. 2, p. 122-133, Dol:10.2346/1.2135249.

[16] Baranowski, P., Malachowski, J., Janiszewski, J. Wekezer, J. (2016). Detailed tire FE modelling with multistage validation for dynamic analysis. Materials and Design, vol. 96, p. 68-79. DOI:10.1016/j.matdes.2016.02.029.

[17] Kucewicz, M., Baranowski, P., Małachowski, J., Popławski, A., Płatek, P. (2018). Modelling, and characterization of 3D printed cellular structures. Materials and Design, vol. 142, p. 177-189, D0l:10.1016/j.matdes.2018.01.028.

[18] Baranowski, P., Malachowski, J., Mazurkiewicz, L. (2016). Numerical and experimental testing of vehicle tyre under impulse loading conditions. International Journal of Mechanical Sciences, vol. 106, p. 346-356, D0I:10.1016/j. ijmecsci.2015.12.028.

[19] Padovan, J., Ma, J., Parris, H. (1995). Millipolar theory for twisted cord-reinforced composites. Tire Science and Technology, vol. 23, no. 3, p. 138-174, Dol:10.2346/1.2137502.
[20] PIdaparti. R.M.V. (1996). Torsional analysis of a steel cordrubber tire belt structure. Tire Science and Technology, vol. 24, no. 4, p. 339-348, D0I:10.2346/1.2137526.

[21] Ebbott, T.G. (1996). An application of finite element-based fracture mechanics analysis to cord-rubber structure. Tire Science and Technology, vol. 24, no. 3, p. 220-235, DOI:10.2346/1.2137520.

[22] Kim, K., Kim, S., Ju, J, Kim, D.M. (2013). contact pressure of a nonpneumatic tire with three-dimensional cellular spokes. Proceedings of the ASME 2011 International Mechanical Engineering Conference \& Exposition, D0l:10.1115/ IMECe2011-64233.

[23] Kim, K., Kim, D. (2011). Contact pressure of nonpneumatic tires with hexagonal lattice spokes. SAE Technical Papers, vol. 1, no. 99, p. 1-13, D0l:10.4271/2011-01-0099.

[24] Lee, C., Ju, J., Kim, D.M. (2012). Vibration analysis of nonpneumatic tires with hexagonal lattice spokes. Proceedings of the ASME 2012 International Engineering Technical Conference \& Computers and Information in Engineering Conference, D0I:10.1115/DETC2012-70538.

[25] Kim, K., Heo, H., Uddin, M., Ju, J., Kim D.M. (2015). Optimization of nonpneumatic tire with hexagonal lattice spokes for reducing rolling resistance. SAE Technical Paper, no. 1515, p. 1-10, D0I:10.4271/2015-01-1515.

[26] Ju, J., Kim, D.M., Kim, K. (2012). Flexible cellular solid spokes of a nonpneumatic tire. Composite Structures, vol. 94, no. 8, p. 2285-2295, D0I:10.1016/j.compstruct.2011.12.022.

[27] Song, H.S., Jung, S.P., Park, T.W. (2018). Simulation of temperature rise within a rolling tire by using $\mathrm{FE}$ analysis. Journal of Mechnical Science and Technology, vol. 32, p. 3419-3425, D0l:10.1007/s12206-018-0645-3.

[28] Nishiyama, K., Nakashima, H., Yoshida, T., Shimizu, H., Miyasaka, J., Ohdoi, K. (2018). FE-DEM with interchangeable modeling for off-road tire traction analysis. Journal of Terramechanics, vol. 78 , p. 15-25, D0l:10.1016/j. jterra.2018.03.005.

[29] Kucewicz, M., Baranowski, P., Małachowski, J. (2017). Airless tire conceptions modeling and simulations. Proceedings of the 13th International Scientific Conference, p. 293-301, DOI:10.1007/978-3-319-50938-9_30.

[30] Guo, H., Bastien, C., Blundell, M., Wood, G. (2014). Development of a detailed aircraft tyre finite element model for safety assessment. Materials and Design, vol. 53, p. 902909, D0I:10.1016/j.matdes.2013.05.046.

[31] Lee, C., Ju, J., Kim, D.M. (2013). Vibration analysis of nonpneumatic tires with hexagonal lattice spokes. International Design Engineering Technical Conferences and Computers and Information in Engineering, D0l:10.1115/ DETC2012-70538.

[32] Zhao, Y.Q., Du, X.B., Lin, F., Wang, Q., Fu, H.X. (2018). Static stiffness characteristics of a new nonpneumatic tire with different hinge structure and distribution. Journal of Mechanical Science and Technology, vol. 32, no. 7, p. 30573064, D0l:10.1007/s12206-018-06 08-8.

[33] Pacejka, H.B. (2012). Tire and Vehicle Dynamics. ButterworthHeinemann, Oxford. 